\title{
LECCIONES DE LA INFORMALIDAD
}

\author{
JORGE HURTADO JORDÁ
}

Departamento de Ciencias Sociales.

Universidad de Alicante.

\section{RESUMEN}

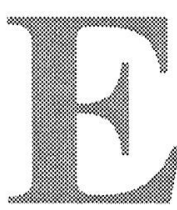

1 artículo sostiene que las crecientes referencias a la informalidad en las dos últimas décadas, desde los más variados paradigmas y contextos socioinstitucionales, y en relación con las más diversas problemáticas, sólo puede entenderse en tanto que «síntoma», aparentemente polimórfico, de una doble crisis. Primero, de las teorías dominantes sobre el desarrollo y el cambio industrial. Segundo, de la crisis de las sobrereguladas economías de los centros mundiales y de los esfuerzos desarrollistas de la periferia. Tras pasar revista al estado de la cuestión en ambas áreas, concluye que la novedad histórica de los procesos de informalización es sólo relativa, y se examina su conexión con la crisis, desde la óptica inaugurada por socioeconomistas como Polanyi, y los teóricos del «enfoque del sistema-mundo». Desde esta perspectiva, la «informalidad» no es una anomalía que requiera explicaciones ad hoc, sino una pauta regular que solicita análisis.

\section{INTRODUCCION}

En las dos últimas décadas el interés por las economías no oficiales -o informales, ocultas, sumergidas, clandestinas, atípicas y un largo etcétera- no ha cesado de crecer, en paralelo a la supuesta extensión efectiva de los fenómenos considerables bajo esa rúbrica en todo tipo de sociedades y economías, tanto en las desarrolladas como en las periféricas, en aquéllas con escasa políticas sociales y de empleo como en los países capitalistas con tradición de intervención estatal fuerte, en las regiones europeas de industrialización tardía como en los Estados-nación del antiguo Segundo Mundo o en los llamados Nuevos Países Industrializados del Pacífico Asiático (Bagnasco, 1986 ; Sanchís y Miñana, 1988; Portes, Castells y Benton, 1989).

En estas condiciones poco puede extrañar que en el mismo periodo el número de monografías y estudios de caso sobre un asunto de perfiles tan elusivos y diversos haya crecido exponencialmente. Pero, además, la invocación, directa o indirecta, a la «informalidad» impregna 
la discusión de asuntos que, en principio, poco tienen que ver con las ideas que el sentido común proyecta sobre el tema, de modo que resulta difícil evitar la impresión de que la informalidad resultó ser, casi desde su origen, una especie de Mc Guffin intelectual.

Permítaseme ahora no hacer una lista que raramente podría ser exhaustiva, y que involucraría los más variados programas de investigación de la totalidad de las ciencias sociales, en una especie de dilución de las habituales fronteras disciplinarias ante la aparición de una problemática tan totalizante como difusa. Ahora bien, puesto que en rigor los fenómenos vinculados a la informalidad no son en absoluto recientes -más bien al contrario-, tal vez podamos concluir que las crecientes referencias a la informalidad, desde los más variados paradigmas y en el contex to de relaciones sociales y de preocupaciones muy diferenciadas, sólo puede entenderse en tanto que «síntoma», en tanto que señal de algo que está sucediendo o que va a suceder. Inicialmente, por supuesto, la informalidad es entendida como indicio de una «crisis». Resta por definir, sin embargo, qué es una crisis y, sobre todo, qué está en crisis.

Desde luego, en primera instancia, la crisis parece atañer sobre todo a las teorías sociales dominantes, construidas aparentemente a través de una selección (interesada) de acontecimientos, que presuponía tanto una cierta autoanestesia histórica como la desatención a amplias colecciones de sucesos de los que la informalidad resultaría ser un signo polimórfico. Al hilo de la informalidad, con la informalidad como pretexto, los textos que, apoyándose en una verdadera avalancha de «estudios de caso» procedentes de las más variadas latitudes, les sobrevivieron, reflejaron y se hicieron eco de todas las perplejidades de las tres últimas décadas, de todas las crisis, desde la crisis de rentabilidad de la integración vertical fordista y su desintegración organizada (la fábrica difusa o fugitiva), hasta la crisis de los dominantes paradigmas sobre el desarrollo, pasando por el debate sobre las causas del paro y sus medidas, de la crisis misma, del Estado en la crisis y de la crisis del Estado.

Al concentrarse, sin embargo, en los detalles del auge de lo «sumergido», emergió como posibilidad alternativa una sorprendente inversión de perspectivas, no muy distinta de la que los «filósofos de la sospecha» impusieron en el campo del saber humano en el gozne del último siglo. Lo «sumergido» resultó ser, así, no ya una «terra incognita», sino el soporte oculto y necesario de lo explícito, de lo digno de consideración, de lo respetable y mensurable -dos términos que han acabado por ser equivalentes en las ciencias sociales-, por todos conocido, por todos « forcluido», un neologismo lacaniano que viene bien a cuento. Lo excluido del acceso a lo simbólico, la representación intolerable, reaparece así masivamente en lo real. 
Al iluminar las zonas de penumbra de las socioeconomías contemporáneas, los autores que inicialmente se contentaron con la contemplación de sombras trémulas en la pared -para retomar la metáfora platónica puesta en circulación por Pahl al respecto de nuestro asunto (Pahl, 1990)-, impusieron en la agenda intelectual del corto siglo XX que agoniza una reordenación radical de categorías y conceptos, una mirada directa a la fogata, un nuevo modo de plantear los problemas, cuya conclusión lógica es la demolición -o el intento de demoliciónde lo que Wallerstein ha denominado la «metafísica del mundo moderno» (Wallerstein, 1990), una amalgama, muy efectiva en los hechos, de occidentalocentrismo, historias ejemplares, relatos de legitimación y tipos ideales, cuyo recorte de la realidad funda un tipo singular de racionalidad que recrea la realidad, cuyo realismo realimenta la racionalidad que evacua la realidad, en una espiral sin fin.

En segundo lugar, sin embargo, en la historia extrínseca a los avatares de la teoría, la emergencia de la informalidad como problema intelectual, como motivo de indagación en las ciencias sociales -ya que, en rigor, las diversas socioeconomías, consideradas en conjunto, son menos informales en las últimas décadas que en las precedentes- bien pudiera considerarse función de una doble crisis entrelazada o, si se quiere, la doble cara de una realidad simultánea y contradictoria: la crisis de las economías altamente institucionalizadas del «centro», y la crisis de los esfuerzos desarrollistas de la «periferia». Apurando esta premisa, tal vez sea el concepto y, sobre todo, la realidad misma del «desarrollo» lo que pudiera estar en crisis, al menos para la mayor parte de la humanidad, de modo que se hiciera necesario suturar la distancia entre imágenes y realidades proponiendo variaciones semánticas del concepto como una especie de Alka-Setzer moral y político.

\section{LA CENTRALIDAD DE LA INFORMALIDAD EN LOS PAÍSES PERIFÉRICOS}

No es extraño, así, que la noción de «informalidad» prosperara inicialmente al contacto con las abigarradas realidades económicas de los países terceros a principios de los años setenta, un periodo crucial en el que empieza a translucirse el fin de la «economía mágica» del modelo de acumulación de la posguerra en los países centrales, y el fiasco de la promesa de integración paulatina en los beneficios del sistema de la periferia «subdesarrollada», como tardíamente fue calificada por Truman (Estevan, 1995). 
Examinando retrospectivamente, sin embargo, el itinerario intelectual de la «informalidad» no puede afirmarse que las polémicas que suscitó fueran esclarecedoras, pero resultaron reveladoras, a su vez sintomáticas. El punto de partida, en efecto, de los estudios sobre la informalidad bien puede describirse como el arduo redescubrimiento de lo obvio, sacrificado en aras de una fe sin esperanza, y de una mal entendida caridad, menos próxima al amor que a la inhabilitante limosna. ¿Qué era obvio y, sin embargo, opaco, rechazado, negligible, informe, subterráneo, oculto, fantasma, sumergido? Lo demasiado notorio, lo manifiesto invisible, lo patente indecible era que una parte sustancial de la actividad laboral y económica en los países terceros se desenvolvía al margen de toda reglamentación legal y, frecuentemente, ajena a todo cómputo oficial. En otros términos, que no acababa de encajar en las categorías convencionales que en los países industrializados daban cuenta de la evolución, socialmente construida, de la producción y del empleo, y que, en consecuencia, una parte no menor de la población mundial sobrevivía inserta en relaciones sociales y económicas difícilmente inteligibles y formalizables a través de dichas categorías , tan pronto puro resto marginal (demasiado numeroso), una supervivencia (demasiado rica y dinámica, en ocasiones), un «sector», una verdadera «economía», una reencontrada «senda al desarrollo», siempre una «nebulosa» demasiado multiforme.

Por así decirlo, el utillaje teórico occidental resultó ser demasiado accidental, primero espacialmente, temporalmente en un segundo momento. Así, los anteojos empezaron a ser vistos, no sin cierto estrabismo, más como anteojeras que como instrumentos que facilitaban la visión. Lo demasiado patente, pero no visible, resaltó las funciones latentes, limitadoras y autopersuasivas, que restringían la comprensión del cambio y de la transición socioeconómica a escala global.

Es, de hecho, mérito asignable a las investigaciones sobre la informalidad el haber contribuido a la demolición de las visiones lineales, esencialistas y reduccionistas -es decir, ahistóricas- sobre el desarro1lo. El carácter intersticial y polimórfico de lo informal, no obstante, no sólo dificulta su definición estricta, sino que ha autorizado interpretaciones contrapuestas que, conteniendo todas un grano de verdad, resaltan una configuración calidoscópica entre todas las posibles (Portes y Schauffler, 1993; Mingione, 1993).

Es cierto, por ejemplo, que la población que afluye a las metrópolis del Tercer Mundo, perdidos sus medios de subsistencia agrícola y arrojada al museo de los horrores urbano de las grandes ciudades periféricas, conforma el grueso ejército de la informalidad marginal (Nun, Martin y Murmis, 1967). Pero un concepto tan macizo y excluyente, asumido por igual por el marxismo y el funcionalismo (Germani, 1980), no toma en consideración no ya el hecho de que dicha población sobrevive en 
los intersticios de la modernidad, nutrida frecuentemente de sus desechos, sino las estrategias de movilidad, de diferenciación interna, las dinámicas, tan ricas como frágiles, que la atraviesan y le otorgan su singular coalescencia.

El mérito de Hart consistió, justamente, en la reivindicación austera de la vitalidad y autonomía de un «sector» que conjugaba contemporánea y resistentemente lo elemental y transitorio, el gesto repetido y lo mínimo y supuestamente abocado a la extinción: la producción de subsistencia directa y para el autoconsumo; la protoindustria artesanal en su infinita variedad; los oficios residuales, callejeros, errantes, vagabundos; el pequeño comercio, tan poco productivo, mínimamente excedentario, poco capitalizado; el delito menor, más o menos vinculado al mercado negro local o a la gran economía criminal transnacionalizada (Hart, 1973).

Dicha caracterización de la informalidad descontaba, sin embargo, al hacer hincapié en el autoempleo, las prácticas de subcontratación de las empresas del «sector moderno», o la «desintegración vertical organizada» de la gran empresa multinacional, que puede devengar salarios muy bajos en presencia de grupos domésticos semiproletarios, y descargar la incertidumbre sobre el trabajo, asalariado de hecho, pero no protegido. Es importante, además, retener que todas esas formas de actividad no se dejan distinguir como las capas de una cebolla, no son esferas autorreferenciales y cerradas. De un lado, las fronteras entre lo formal y lo informal no sólo son móviles, sino que ambos ámbitos se interpenetran, se parasitan, se solapan, se anudan en lazos insólitos. La economía oficial monetaria, por ejemplo, coloniza las economías no oficiales, extrae de ellas la parte del león del beneficio, les exporta sus tareas ininteresantes, rutinarias, y los riesgos derivados de las oscilaciones del mercado. A su vez, la informalidad se nutre frecuentemente de los desechos de la economía formal, ocupa los nichos sin salida en la economía regular, oficia sus prácticas en las desgarraduras o en los límites del mercado y, al estar sujeta a restricciones económicas y sociales indisolublemente unidas, opone límites severos a la mercantilización progresiva. De otro lado, entre las distintas formas de la informalidad, y entre lo formal y lo informal, los límites son fluidos y la reversibilidad la norma, al resultar una pauta regular la compatibilización de distintas fuentes de ingreso para la supervivencia.

Como han puesto de relieve con vigor Portes y Castells, la informalidad no es, así, asimilable, sin más, a «marginalidad», una forma púdica de aludir a una situación de derelicción e irrelevancia en el sistema mundial. Tampoco representa, simplemente, la supervivencia de relaciones sociales y de formas de trabajo abocadas a la extinción, o 
reactualizadas en una situación de crisis (Portes y Castells, 1989). En muchos sentidos, por el contrario, las prácticas informales arraigan en un suelo nuevo, suponen una reinterpretación de antiguas relaciones sociales, y constituyen una manifestación viva de resistencia frente a las presiones competitivas de mercado, una prueba de las dificultades del sistema para ampliar la mercantilización, como han señalado, entre otros, Arrighi y Mingione (Arrighi, 1987; Mingione, 1993).

Este es, en efecto, el Talón de Aquiles de las interpretaciones liberales de la informalidad que, al resaltar, no sin motivo, los «mecanismos de exclusión» utilizados por las magras élites (económicas y laborales) de los Estados Mercantilistas frente al desafío de los «informales», incurren en la apología de un «capitalismo popular», de un «capitalismo descalzo», que resultaría ser el subrepticio sendero, recién redescubierto, de la «nueva riqueza de las naciones» en la era de la riqueza planetaria, una demostración adicional de la futilidad/perversidad de las regulaciones frente a la potencia creadora del mercado (de Soto, 1987).

No es necesario, sin embargo, evocar la contradicción en los términos de un «capitalismo popular», para convenir: $1^{\circ}$ ) que la informalidad ha arraigado también con singular fuerza, y con éxito más duradero, en socioeconomías en las que las instituciones políticas han jugado un papel relevante en la promoción del desarrollo, como es el caso de la Tercera Italia o de los Nuevos Países Industrializados (Capecchi, 1988; Bustelo, 1990); $2^{\circ}$ ) que el aspecto distintivo de las actividades informales «autónomas»-es decir, no presas en las redes de subcontratación de la gran empresa- es justamente su «racionalidad» poco capitalista, su inserción en relaciones sociales y vínculos culturales densos e idiosincrásicos, frente a la desinserción y autonomía de lo económico allí donde predominan las presiones competitivas de mercado.

En la estela de Hart, en efecto, han sido numerosos los autores e instituciones que han documentado profusamente que la «racionalidad productiva» de la empresa informal es netamente distinguible de la de la empresa, digamos, capitalista (Martínez Veiga, 1989; Ybarra, 1991). Mientras que el objetivo de esta última es la generación de excedentes y la acumulación de beneficios, el fin de las actividades informales es, más simple pero más complejamente, asegurar la supervivencia de los grupos domésticos y, al tiempo, reforzar los vínculos socioculturales que les dan soporte, y que constituyen la garantía de su continuidad. Los intentos de «formalización», la sujección a las reglas del mercado mundial, en detrimento de su orientación local, lejos de sostener la perdurabilidad de la empresa informal autónoma, contribuye, normalmente, a la desregulación del sector formal y a la promoción de una dinámica de autoinformalización en favor del «frente popular del ver- 
dadero capital», puro flujo desterritorializado que incorpora valor y que socava las identidades socioterritoriales locales.

Es cierto que, en algunos espacios, tales como Japón, la Tercera Italia, Miami, o los N.P.I.s, la protoindustralización sobre bases locales desembocó en una movilidad ascendente en la División Internacional del Trabajo. La «ejemplaridad» de dichas trayectoria exitosas, sin embargo, no debiera distraernos: $1^{\circ}$ ) sobre las excepcionales circunstancias endógenas, no generables «ex nihil», que concurrieron en favor de sus logros, bien sea una cultura empresarial extensa, una fuerte identidad colectiva, o unas eficientes instituciones políticas; $2^{\circ}$ ) sobre las, probablemente, más importantes circunstancias exógenas y contingentes - político/militares, «guerrafriístas»-, que favorecieron la activación de dichas potencialidades; $3^{\circ}$ ) sobre el «forcing social», regularmente silenciado, que subyace al éxito de poblaciones culturalmente homogéneas y con escaso peso demográfico, y que, como ha puesto de relieve recientemente Krugman, permite entender dichos «milagros», en su ejemplaridad, como una nueva variante de «acumulación extensiva»; $4^{\circ}$ ) en fin, sobre el hecho de que resulta enteramente ilusorio sostener que la abigarrada infraeconomía de los países terceros pudiera afrontar, en tanto que conjunto significativo, la liza competitiva en la economía globalizada.

Coincido, así, con Giddens y Latouche, en que la «informalidad», cuando es autónoma, no es una reencontrada senda al desarrollo, una inesperadamente nueva estrategia de crecimiento, sino un «hecho social total», una sociedad alternativa, una respuesta de grupos «atrapados entre las tradiciones perdidas y una modernidad imposible». No tanto, en fin, un desarrollo alternativo, sino una alternativa al desarrollo y al productivismo desorganizador de la sociabilidad, un dique frente a la mercantilización progresiva, la autonomización de lo económico, y la introyección de la compulsión laboral como motivación emancipada de otras áreas del mundo de la vida (Latouche, 1993: 89-109; Giddens, 1996: 172-173).

Ahora bien, si la «informalidad» no es, simplemente, una forma púdica de aludir a la marginalidad, la «sociedad informal» tampoco resulta ser monótonamente la denominación contemporánea de una «cultura de la pobreza» digna, menos aceda que la «gran sociedad», probablemente más próxima a la «alegría de vivir» si, en su relativa fragilidad, no es presa del desarraigo, de la ausencia elemental de recursos, de la inseguridad y violencia, de la pérdida radical de autonomía y dignidad.

Cuando la «sociedad informal» es desarticulada/rearticulada al dictado del mercado mundial -o cuando los «procesos de informalización» responden a su impulso-, la informalidad acarrea regularmente una aguda desorganización social, una feroz lucha de todos contra todos, 
una competencia anómica por recursos muy escasos, junto con la extensión de un «taylorismo salvaje», y la reactivación de todas las formas de trabajo conocidas, incluidas la servidumbre, la esclavitud, o la sobreexplotación del trabajo infantil.

Resulta ilusorio -0 , peor aún, confuso y confundiente-, sin embargo, intentar comprender tales situaciones como parte de tendencias en favor de la informalización, desatadas a escala mundial en las últimas décadas. La informalización presupone una formalización previa, la presencia de regulaciones institucionales y la capacidad para hacerlas cumplir, condiciones que no se dan en los países periféricos y en buena parte de los semiperiféricos, en los que las exigencias normativa, adaptadas al nivel de productividad de las empresas competitivas, pierden tácitamente su vigencia en los sectores tradicionales -en las pequeñas explotaciones agrarias, en la construcción, en las industrias de demanda débil, en los servicios personales y distributivos, etc.-.

Los límites entre la formalidad y la informalidad, además, son móviles y porosos, tanto espacial como temporalmente, de modo que lo que era irregular apenas hace una década, hoy bien puede ser enteramente regular, aunque precario, en una u otra dimensión laboral o en todas ellas. Del mismo modo, en las distintas áreas de la economía mundial, actividades similares pueden realizarse en condiciones de regulación muy distintas, o haber permanecido al margen de toda regulación, lo que convierte en fútiles las comparaciones transnacionales sobre la economía informal, y pone plomo en las alas de los afanes cuantificadores sobre una base nacional .

Como subrayó, en efecto, tempranamente Pahl, la comprensión de la informalidad se vio inicialmente lastrada por una perspectiva gerencial y economicista, que amputaba las relaciones económicas de las más amplias relaciones sociales que les dan soporte y determinan su carácter: progresivo o regresivo; virtud, necesidad, o necesidad hecha virtud; inductor de crecimiento o sobreexplotador; vivaz e inventivo, rico en lecciones laborales y en elecciones vitales, o claustrofóbico y superviviente; autónomo o dependiente (Pahl, 1990. 1991).

\section{AQUILES Y LA TORTUGA: LA INFORMALIDAD EN LA SO- CIEDAD INFORMACIONAL}

No creo, por otra parte, exagerar si afirmo que la brecha abierta por Pahl permitió no sólo un nuevo enfoque de la «informalidad». Precipitó una reconceptualización del «trabajo»-una noción, paradójicamente, tan central en la modernidad como elusiva- $y$, a su través, de la actividad económica, de la «vida material», para diferenciar los gestos universales y panhumanos de la producción y de la reproducción de su 
deliberada reducción en la moderna «crematística», la teología de un mundo sin historia (Freyssenet, 1994).

No voy a reproducir aquí los perfiles de esa reconceptualización, que además desató una reevaluación de los finos hilos que mantienen, aparentemente unidas, distintas formas de economía en una sola economía, diferenciadas pero con puntos de contacto, distintas pero superpuestas y alimentándose subálveamente, aunque duramente verticalizadas, comensalista el nivel superior de la infraeconomía que finge ignorar, de la que apenas accede a la consideración y al estatuto, de la informe y desestructurada.

Se acepta hoy, no obstante, sin ambages que lo que hemos convenido en denominar trabajo -el «trabajo libre», el empleo asalariado en el sector formal de la economía- no sólo es una invención reciente, no más antigua que el capitalismo fabril, sino que es un tipo de ocupación mucho menos normal y dominante -en el sentido estadístico- de lo que se supone, incluso en las sociedades avanzadas, y a mayor abundamiento en las menos desarrolladas.

Es posible, de hecho, que buena parte de las sociedades preindustriales carecieran de un término positivo para designar el «trabajo», sin duda porque las actividades de subsistencia no eran fácilmente distinguibles, ni espacial ni temporalmente, de otras actividades que permitían a los grupos domésticos salir adelante (Chamoux, 1994). La evidencia histórica -y hasta filológica- de que el trabajo -y el concepto que tenemos del mismo- es una realidad históricamente construida, resalta, así, al considerar la extraordinaria mutación que cobra forma con el industrialismo, y que es consecuencia de transformaciones materiales (sociotécnicas), pero que concita también admirables metamorfosis culturales y mentales (Polanyi, 1989; Wallerstein, 1990; Gorz, 1995)

No puedo ni siquiera sugerir aquí a través de qué vías las actividades que proveían el sustento dejaron de formar parte íntegra de la vida para constituirse, primero, en el «medio» para ganarse la vida; posteriormente, en una motivación emancipada y autónoma, una verdadera mutación antropológica que habría de desembocar necesariamente - como ya previó Gramsci- en la conversión de los «capitanes de empresa» en verdaderos «capitanes de las conciencias».

Probablemente fue Weber el primero que llamó la atención sobre el carácter compulsivo, y potencialmente adictivo, del «trabajo»-en tanto que empleo remunerado, separado del resto de esferas de la vida-en el orden moderno. La genealogía weberiana de la introyección de la compulsión laboral es, sin embargo, cuanto menos dudosa, tan precisa en la comprensión como borrosa en la explicación. El «arreglo» post hoc, en una reciente obra de Giddens, de la tesis weberiana, en el sentido de un impulso originario del «protestantismo ascético» que, eman- 
cipado de la necesidad, se prolongaría como obsesión viscosa, permeando al conjunto de la sociedad, resulta igualmente poco convincente y, desde luego, ahistórico (Giddens, op. cit: 182).

Creo que puede mantenerse, así, no sin riesgo consciente de tachadura de verdades prácticas, útiles en las políticas de la vida, que la ruptura del equilibrio entre las formas de trabajo «tradicionales»-las múltiples formas de trabajo doméstico y para el autoconsumo, la pequeña producción, el trabajo comunitario, la agricultura de subsistencia etc. $-y$ «modernas» - es decir, el «trabajo libre» asalariado- no tuvo su origen en la emergencia de una nueva cosmovisión, en la modificación aleatoria de las gramáticas mentales, sino en la dinámica misma del capitalismo.

Hay muchas formas -más o menos analíticas, más o menos narrativas- de describir esa ruptura y sus consecuencias imprevistas que, casi siempre en relación directa o indirecta con la informalidad, han vuelto a ser objeto de reconsideración desde mediados de los ochenta. Ahora bien, las tendencias seculares a la proletarización -un proceso históricamente constatable- han sido enjuiciados, a la luz de los problemas actuales de la precarización y del desempleo, desde perspectivas bien distintas, no sólo en función de las tradiciones intelectuales de referencia, sino de la unidad de análisis considerada.

En los países avanzados, autores de orientación muy diversa han llamado la atención sobre el hecho de que la evolución de las sociedades industrializadas se caracterizaría porque conduce a la fuerza de trabajo a una especie de «trampa de la modernización». Desde, al menos, la Segunda Revolución Industrial, el empleo asalariado habría parecido, en efecto, tan remunerador frente a todas las otras formas de trabajo, que el equilibrio inestable entre ambas formas de trabajo fue extinguiéndose en la segunda mitad del siglo XX, restando autonomía al trabajador proletarizado, que ve amenazada su existencia en cada nuevo ciclo de crisis y de desempleo, perdidas progresivamente las prácticas y usos tradicionales de provisión de recursos e incrementada su dependencia, cada vez más exclusiva, de las rentas salariales ( $\mathrm{Pahl}$, 1991; Gorz, 1994; Offe, 1994).

Si se acepta, en cambio, el «enfoque del sistema-mundo», la progresiva mercantilización de la fuerza de trabajo constituye la amenaza más radical para el sistema, existiendo pocas dudas sobre el hecho de que la extracción de excedente es muy superior en las unidades domésticas semiproletarias que en las plenamente proletarizadas. Los trabajadores, incluso en los países periféricos, estarían así objetivamente interesados en su propia proletarización como la vía más útil para incrementar sus ingresos, disminuir la carga de trabajo y proseguir a niveles más altos su lucha por los beneficios, como documentan las masivas migraciones del campo a la ciudad en el último tercio del siglo 
que, sin embargo, nutrieron menos las filas del proletariado tradicional que las de la informalidad (Hobsbawm, 1995: 368). Por contra, en realidad nada más indeseable para los acumuladores como clase que el ahondamiento de la mercantilización del trabajo, que desemboca necesariamente en el incremento de las rentas salariales como porcentaje total de los ingresos, e induce presiones estructurales en favor de su constante elevación (Balibar y Wallerstein, 1991).

$\mathrm{Si}$, a pesar de su indeseabilidad para el agente central del sistema, la proletarización ha avanzado, a lo largo de los últimos siglos, es por tanto función de un doble fenómeno. Primero, porque a diferencia de sistemas sociales anteriores, el capitalismo genera constantemente innovaciones y presiones competitivas que tienden a quebrar cualquier orden consuetudinario, de modo que el interés de los productores/empresarios, en tanto que clase colectiva, choca regularmente con el interés de determinados acumuladores individuales en incrementar su ventaja proletarizando un sector limitado de trabajadores en determinadas áreas. La consecuencia históricamente más visible de este proceso es la constante reestructuración geográfica del sistema mundial siguiendo el «ciclo del producto», y la incorporación de nuevas áreas a la economía-mundo capitalista. En segundo lugar, la causa fundamental de dichos reajustes cíclicos guarda relación con la ausencia de una demanda mundial suficiente, como consecuencia de la distinta consideración de la fuerza de trabajo -en tanto que «coste», o en tanto que «factor de demanda»- por parte de los productores/empresarios, bien como individuos o como clase colectiva.

Ahora bien, incrementos significativos de la demanda son incompatibles con la obtención de una parte sustancial de los ingresos necesarios para la supervivencia de los grupos familiares fuera de los circuitos del trabajo mercantilizado, a través del trabajo doméstico o comunitario y de la producción simple de mercancías. Como han puesto de relieve los «teóricos de la regulación», éste es el «nudo gordiano» de la acumulación que desató el fordismo, a través del ajuste entre el crecimiento de la productividad y el consumo masivo, y una gestión de la reproducción de la fuerza de trabajo que garantizaba un salario familiar suficiente, pero que suponía también la exclusión implícita del mercado de trabajo regular de determinadas categorías sociales. Al fin y al cabo, como subrayó vigorosamente Polanyi, el trabajo constituye una «mercancía peculiar», por lo que el mercado sólo cumple funciones parciales en la regulación de la oferta y la demanda, no pudiendo funcionar sino mediante la exclusión de un buen número de individuos y de categorías sociales enteras (Polanyi, op. cit : 125-128). Aprovechando su «centralidad» en los procesos productivos de las cadenas de mercancías con mayor valor añadido, y las transferencias de plusvalía desde las nuevas áreas incorporadas al sistema mundial, determinadas 
categorías de trabajadores de los países centrales pudieron, así, ponerse al resguardo de las presiones competitivas del mercado. A raíz de la crisis, sin embargo, la globalización pondrá de relieve que la ampliación de la proletarización se dirime hoy a escala mundial, y que el progreso de la mercantilización no es unilineal ni constante en las distintas áreas, ni para los distintos grupos en el interior del sistema, como la experiencia histórica atestigua, ni en lo que se refiere a los países avanzados; ni a los periféricos, ni en la relación que une a los unos con los otros (Wallerstein, 1985, 1988; Boyer, 1992, 1994).

Debemos, así, primero, despojar al concepto de «crisis» de sus connotaciones de depresión y malestar, del mismo modo que las fases de auge no equivalen a bienestar para todos. Si el escenario del sistema, y de lás crisis del sistema, no es una u otra de las distintas áreas que lo componen, sino el sistema mundial como un todo, las nociones de crisis y de prosperidad son relativas desde el punto de vista de los distintos grupos particulares del sistema. La situación de determinadas áreas en la División Internacional del Trabajo mejora ostensiblemente, mientras que se deteriora la posición de otras. El descenso del empleo asalariado en unas zonas puede verse compensado con creces por su ascenso en nuevas localizaciones. Las tendencias a la asalarización regular pueden invertirse, al tiempo que mejoran los salarios y las oportunidades de los que permanecen empleados. La división social del trabajo entre los sexos, las etnias y los grupos de edad pueden variar, de modo que las mejoras y desventajas hagan que se modifiquen los marcos institucionales y las formas de conflicto. De hecho, como ha señalado con acierto Mingione, frente a las imágenes convencionales del marxismo," pero también de la sociología académica, la profundización de la proletarización no ha supuesto la homogeneización de la fuerza de trabajo, sino que en muchos sentidos ha provocado y requerido sus fragmentación, su desagregación, aprovechando y ampliando líneas de segregación preexistentes al capitalismo mismo (Mingione, op. cit.: 531-557).

En la historia intelectual de las dos últimas décadas, los procesos de informalización son, así, interpretados en función de las preocupaciones de cada periodo (Capiello 1987 ). En los países avanzados, por ejemplo, los procesos de informalización parecen vincularse, en un primer momento, a las descentralizaciones productivas de la gran fábrica fordista (Frey, 1975; Garofoli, 1978; Celada, López y Parra, 1985). Pronto, sin embargo, se convino que los procesos de informalización habían jugado un papel decisivo en los países de industrialización reciente, en los que persistían, aunque con una funcionalidad diferente, y que se expandían, bajo múltiples formas, en los mismos centros mundiales de antigua industrialización, de modo que los iniciales afanes cuantificadores y los problemas de cálculo cedieron en favor de la 
problematización de las teorías sobre el desarrollo y sus vías (Fuá, 1984; Sanchís, 1984; Bagnasco, 1988).

No sólo se constata, en fin, que prosigue y se amplía el doble trabajo y la compatibilización de diversas formas de actividad laboral en el seno de los grupos domésticos, sino que crece el autoempleo en detrimento del trabajo asalariado, y se expande la subcontratación y el empleo precario frente a la contratación regular, al tiempo que, contra las tendencias predicadas, el número de microempresas y el porcentaje de población ocupada en las mismas en vez de disminuir ha venido engrosándose constantemente desde la segunda mitad de los sesenta, favoreciendo bien dinámicas de crecimiento y de flexibilidad ofensiva, bien una flexibilidad defensiva y el retorno de una acumulación de corte extensivo (Gallino, 1983; Sabel, 1985). Como en la aporía de Zenón, el Aquiles informacional no parece estar aún en condiciones de atrapar a la tortuga informal, que empieza a ser oscuramente comprendida no como «resto» de lo real oficial sino, como el azogue, precondición y parte integral del espejo.

No me detendré en las funciones ideológicas latentes que la informalidad cumple en los discursos oficiales de las instituciones implicadas en las relaciones laborales -Gobiernos, Patronal, Sindicatos-, ni en su caracterización, frecuentemente interesada y ambigua, de sus causas y consecuencias (Tortosa, 1988). Desde la segunda mitad de los setenta, además, acogidas bajo el dúctil marco de la informalidad, se «redescubren» (sic) realidades muy diversas, que desatan un incierto furor taxonómico cuya desembocadura es un replanteamiento, a bastonazos de ciego, de las realidades económicas, de sus regiones transparentes y de sus zonas de sombra, a veces aparentemente autónomas, a veces claramente vinculadas, siempre anudadas por lazos más sutiles y estrechos que los postulados por las troceadas visiones de la economía convencional (Sachs, 1983; Gershuny y Pahl, 1983; Capecchi y Pesce, 1985).

Lentamente, sin embargo, apoyándose en una confusa avalancha de «estudios de caso» y de infatigables distingos, la informalidad se disuelve en tanto que objeto teórico autónomo, pasando a ser considerada simplemente una prueba adicional de la insoportable gravedad de las regulaciones fordistas/beveridgeanas /keynesianas, el banco de pruebas de la necesaria desregulación del mercado de trabajo (Ybarra, 1988), al tiempo que sobre el amplio campo roturado por las discusiones sobre la informalidad emergen y destacan tres vastas áreas de debate y estudio, que parecen reclamar una atención más cuidadosa, una reevaluación de las realidades solapadas, de su espesor y de sus vínculos. La primera se refiere a las teorías dominantes sobre el desarrollo y el cambio industrial que, fascinadas por la implícita teleología del «progreso», habrían incurrido en permanentes ejercicios de sinécdoque in- 
telectual, y minusvalorado la persistencia de diversas formas de trabajo irregular -«no libre»-en el seno de tendencias estructurales y unilineales en favor de la industrialización y de la proletarización. La segunda concierne a las respuestas (históricas) frente a las crisis cíclicas del capitalismo, y su novedad relativa, es decir, al hecho de si la persistencia (o la recuperación) de formas de trabajo supuestamente «tradicionales» cumplen (o no) funciones nuevas en contextos espacio/temporales diversos y cambiantes. La tercera, en fin, guarda relación con el papel concreto cumplido por los procesos de informalización, en su heterogeneidad, en el seno de la actual crisis, sus mecanismos estructurales, su significado y sus consecuencias.

Resulta, obviamente, imposible intentar trazar aquí siquiera un mapa elemental de las distintas respuestas a dichos «themata», cuya síntesis más elocuente bien pudiera ser la seminal obra de Mingione (Mingione, op. cit.). Me ceñiré, en consecuencia, a enunciar algunas proposiciones que son tributarias de las solitarias obras de Braudel y de Polanyi, transcritas en el tapiz contemporáneo que anuda sus hilos perceptibles: el «enfoque de los sistemas-mundo» y, sobre todo, la sociología histórica de Immanuel Wallerstein.

Desde esta óptica, en efecto, la aportación decisiva de la renovada atención a los procesos de informalización no deriva ni de la discusión sobre su participación en los procesos actuales de desarrollo en los países periféricos y semiperiféricos, ni del debate sobre su papel en los procesos de desregulación iniciados en los países centrales tras la crisis de los años sesenta y setenta. Ahora bien, la atención a esos fenómenos, que contravenían supuestas tendencias típicas del industrialismo, permitió tanto reevaluar su persistencia inadvertida en el seno mismo de las economías altamente institucionalizadas durante el periodo 1950-1973, como desplazar, en un momento posterior, el foco de atención intelectual en favor de colecciones de sucesos que, considerados «anomalías» de un movimiento unilineal, resultaron ser la regla y no una excrecencia coyunturalmente excepcional.

Desde esta enfoque, que invierte las prioridades regulares de examen en las ciencias sociales, las «anomalías» no son excepciones que requieren explicaciones ad hoc, sino pautas que solicitan análisis (Wallerstein, 1990: 412). Podemos, así, distinguir un conjunto de proposiciones teóricas y de descripciones de acontecimientos que más que instrumentos útiles de observación han resultado ser una especie de obstáculo, unas anteojeras que en sí mismas requieren análisis, que demandan esclarecimiento. Una de esas pautas se refiere a las variedades efectivas de industrialización, secuestradas por la imagen de «una Revolución Industrial»-la inglesa durante el siglo XVIII-, convertida en paradigma de «la» Revolución Industrial, cuando ni siquiera su realidad histórica se aviene con los principios enunciados, como puso de 
relieve la Escuela Revisionista de la protoindustrialización (Berg, 1987; Kriedte, 1986). Otra de esas instituciones es el «mercado», una estructura marginal hasta prácticamente el siglo XIX -como mantendrán, pese a sus diferencias, tanto Braudel como Polanyi-, y abusivamente identificado con el «capitalismo» (Braudel, 1984, 1985).

La «informalidad» resulta ser, así, primero, un avatar contemporáneo de la «vida material», la forma básica de actividad económica antes del siglo XIX, sobre cuyas anchas espaldas reposa el «mercado» y despliega el capital sus prácticas monopolistas en alianza con el Estado, y que incluye el vasto mundo de los gestos de la reproducción, el autoconsumo, el trueque no monetario, la producción simple de mercancías para el mercado, las formas de trabajo asalariado inestables, no protegidas o con diversos grados de irregularidad, etc (Braudel, 1984, vol. I: 2-3, 6-7). De creer a Polanyi, además, las presiones competitivas de mercado no podrían persistir de no imbricarse en otras formas de intercambio - la reciprocidad, la redistribución-, ya que la lógica del mercado es contraria a toda forma de sociabilidad y disolvente de la misma. Es, por decirlo con Mingione, un organizador económico que no podría subsistir sin su inserción en otros factores socioorganizativos que el individualismo y la competencia de mercado no pueden generar y que, a largo plazo, contribuyen a erosionar (Mingione, op. cit.: 4041, 63).

Ahora bien, partiendo de estas hipótesis el modo de plantear los problemas se invierte radicalmente. La imagen de «trabajadores libres», exclusivamente dependientes para su subsistencia de salarios monetarios devengados por «empresarios libres», resulta parcial y engañosa, sosteniéndose además sobre otras formas de trabajo que son consideradas «no trabajo», y que representan una subvención indirecta a los empleadores. Lo verdaderamente relevante, entonces, no es que se hayan invertido las tendencias a la proletarización -una afirmación incierta para el conjunto del sistema mundial-, sino por qué ésta es tan limitada incluso en los países avanzados (Wallerstein 1988: 12). Más aún, al observar sin anteojeras todas las formas de trabajo y de extracción del excedente aún hoy existentes y en absoluto marginales, no puede sino concluirse que las continuidades predominan sobre los cambios, y que las tendencias operantes en el núcleo orgánico del sistema mundial se han visto, hasta el presente, contrarrestadas por la incorporación de nuevas áreas en las que predominan grupos domésticos semiproletarios para los que los ingresos monetarios sólo son una parte del total de sus ingresos (Braudel 1984, vol II: 257-258; Wallerstein, 1988: 1).

Así, lo que la discusión sobre la informalidad revela, en último término, es una concepción irreal y ahistórica del funcionamiento del capitalismo, según la cual existen países más o menos capitalistas en una 
gradación sugerida por indicadores complacientemente convencionales. Frente a la misma; el «enfoque de los sistemas-mundo» sostendrá que el capitalismo es un sistema mundial en el que hoy, como en el siglo XVII, encontramos una yuxtaposición y coexistencia de sociedades y economías muy diversas. En palabras de Braudel, un escalonamiento regular según el cual las zonas centrales se nutren de las periféricas e imponen a éstas sus leyes y necesidades, y en el que simultáneamente se dan distintos niveles de desarrollo y todas las formas de trabajo y de extracción del excedente conocidas (Braudel, 1985: 75). Cuestión bien distinta, sin embargo, como he señalado anteriormente, es por qué avanza la «proletarización» -es decir, el hecho de que un número creciente de grupos domésticos dependa de rentas salariales para su subsistencia-, y si éste es un proceso lineal en las distintas áreas del sistema-mundo.

\section{LA INFORMALIDAD Y LA CRISIS}

Se ha sostenido, en efecto, que la recuperación de formas de trabajo supuestamente periclitadas o antiguas en un nuevo contexto cumple también funciones nuevas. La informalidad no supone, de hecho, simplemente el retorno de las «sweatshop». Es también la reorganización productiva del sistema de fábrica y de otras actividades desreguladas como la nueva «economía virtual», la que opera en el ciberespacio de las geofinanzas: los derivados, los futuros, las opciones, los swap - la que ha permitido la extensión de la informalidad, tras un largo periodo de control institucional y de activa intervención del Estado, instaurando la opacidad en un doble nivel, como ya observara Braudel. Abajo, la «vida material», masiva y pulsional, una infraeconomía que apenas accede a la categoría de «acontecimiento», parcialmente sustraída al mercado, y cuya importancia reposa en su repetición multiplicada. Arriba, el «visitante nocturno», minoritario y cultivado, monopolista y parasitario de las actividades que le son subyacentes, pese a presentarse como adalid e instrumento de la competencia, motor y plenitud del desarrollo económico, agente de la especialización y de la división del trabajo. Lo distintivo, sin embargo, del «capitalismo» es su capacidad para eludir la competencia, frente a las presiones constantes de la economía de mercado, y su simbiosis con el Estado, del que se nutre con liberalidad y del que requiere cierta debilidad y complacencia (Braudel, 1984, Vol III: 527-528; 1985: 87), manifiestas hoy en la desregulación de los mercados financieros, la reclamación de un «global market place» abandonado a la libre actuación de las fuerzas privadas, o la neutralidad frente a las operaciones fiscales de las multinacionales. 
Todo depende, en consecuencia, del significado que demos a los conceptos de «antigüedad» y de «novedad» en las distintas áreas de la economía-mundo, a lo largo de los últimos siglos. Lo que encontramos, de hecho, en el capitalismo histórico no es una evolución lineal de las economías, ni una gradación ordenada de las sociedades -más o menos capitalistas, más o menos industriales o postindustriales-, sino un sincronismo, una simultaneidad de situaciones, que conviven afectándose y/o que son recreadas cuando la situación lo requiere. La economía, en fin, del mundo entero, no sólo «se hace visible en un auténtico mapa de relieve» (Braudel, 1985: 45), sino que cualquier periodo histórico atestigua una combinación de distintas formas de trabajo y de modos de organizar la producción, aunque en proporciones distintas, que no excluye ni la recreación de las más antiguas y vejatorias, como la esclavitud que, después de haber desaparecido en Occidente durante siglos, recobra un renovado vigor a partir del siglo XVI.

Confrontados, por tanto, los procesos de informalización en los países centrales con las tendencias regulares en el modelo de acumulación de la posguerra sugieren, ciertamente, no sólo una funcionalidad diferente, sino una muy real inversión de las pautas de desarrollo fordiano. En una perspectiva de larga duración, dicha inversión resulta, no obstante, enteramente regular, al menos en el capitalismo histórico, como profusamente documentó Braudel, para la economía-mundo europea, entre los siglos XIII y XVIII. Cuando se incrementa peligrosamente la fuerza estructural del trabajo organizado en los centros mundiales, los precios crecen en exceso, surgen nuevos competidores en la arena mundial, y se intensifican dramáticamente las fatales tendencias a la asalarización -la modalidad de trabajo más costosa-, las fábricas se trasladan al campo, y se inicia una fase de ajustes que, un tanto melodramáticamente, denominamos crisis (Braudel, 1984, vol. II: 263). Dichos ajustes pueden resumirse en: la quiebra masiva de empresas ineficientes, aunque protegidas, sostenidas políticamente; el incremento de la intensidad de capital en los procesos productivos, a través de innovaciones tecnológicas menores, cuya consecuencia es el desempleo tecnológico; la relocalización espacial de determinadas actividades desde las áreas centrales a las semiperiféricas y a algunas periféricas, siguiendo el «ciclo del producto» de Vernon; el ajuste de las rentas de las burguesías asalariadas de los centros mundiales; y la puesta a punto y la explotación de innovaciones técnicas radicales que constituirán la base del nuevo modelo de acumulación (Wallerstein, 1983: 21-22).

Ahora bien, desde el punto de vista de nuestro interés, el aspecto decisivo es que la reducción de la producción, a través de las quiebras de empresas, las deslocalizaciones y la innovación tecnológica, incrementan el desempleo y el subempleo encubierto, que resulta ser 
un arma decisiva para el control de los costes, la erosión del poder del trabajo organizado, y el freno de las tendencias a la asalarización regular en los países centrales, compensado por la proletarización parcial de nuevos grupos domésticos en áreas de bajos salarios que, a corto plazo, equilibran los riesgos de la asalarización.

Esta pauta, habitual en la economía-mundo europea entre los siglos XIII y XVIII, tiene hoy como escenario el conjunto del sistema-mundo, y explica, hogaño como antaño, el recurso a otras formas de actividad laboral irregulares, la desagregación del trabajo, y la reactivación del autoconsumo y de la economía doméstica y comunitaria en los países avanzados, como una especie de «segundo teclado» económico, como una alternativa «flexible» a los atolladeros de la acumulación Todo sucede, en fin, como si la dinámica de la acumulación operara a través de la quebrada lógica de «un paso adelante, dos atrás», apoyándose en la progresiva concentración y centralización del capital y de los procesos productivos, por una parte, y en la ampliación del denominador de la ecuación, por otra, es decir, en la desconcentración de la producción, la reactivación y recreación constante de la «vida material» adaptada a las nuevas condiciones, y la ampliación parcial de la mercantilización a nuevas áreas y actividades. Dicho proceso, sin embargo, no es lineal ni acumulativo, sino calidoscópico y contradictorio -como sugirieron certeramente Gershuny y Pahl (1983)-, a pesar de sus límites: la finitud del mundo y de sus recursos. La actual crisis, en efecto, difiere de las crisis históricas anteriores en que complica varias crisis. No hay que pensar, por ello, que la desaparición del capitalismo como sistema comporte el triunfo de un sistema más libre, más igualitario o más fraterno, más atento a las necesidades básicas o a la sostenibilidad de la vida. Sus mecanismos, sin embargo, diferirán de los típicos del capitalismo en los últimos siglos (Wallerstein, 1993).

No es incorrecto, por tanto, vincular la expansión de la informalidad con la/s crisis, aunque es necesario determinar primero qué se entiende por crisis. Desde la óptica adoptada aquí, la crisis es una consecuencia de la disyunción entre la oferta y la demanda, en la medida en que ambos se rigen por principios diferentes. Mientras que la oferta es consecuencia de decisiones individuales, tomadas con vistas a la acumulación, la demanda depende de la distribución del excedente y de la lucha por los beneficios en las distintas áreas del sistema-mundo. Es una consecuencia, pues, de relaciones de fuerza que se dirimen a nivel mundial, y que desembocan en compromisos consuetudinarios a medio plazo, que despejan las incertidumbres. Dichos compromisos, a su vez, quiebran cuando, a partir de un punto, la rentabilidad de los productos de las empresas líderes decrece, debido tanto a la afluencia de nuevos productores, que se benefician de costes más bajos, como del éxito organizativo del trabajo (Arrhigi, 1983.; Wallerstein, 1985). En 
la actual crisis coinciden, además, una Fase B de un Ciclo Kondratiev y una «crisis de hegemonía», que dilata la resolución de las luchas por los beneficios a nivel mundial y dificulta las «inversiones de control en el mercado mundial» -es decir, según Gordon, no sólo la infraestructura global en nuevos transportes y redes de comunicación, de telecomunicación, etc., sino la infraestructura político/militar del Ejército Imperial, incluyendo las acciones no declarables o invisibles-. No puede descartarse, por otra parte, como señala Wallerstein, que el capitalismo, como sistema histórico, esté agotando su ciclo, agotamiento preludiado por su expansión absoluta $\mathrm{y}$, sobre todo, por límites ecológicos infranqueables, cuando para el capital la expansión lo es todo y el equilibrio nada.

Es la conjunción, en fin, de varias crisis la que dota al actual periodo recesivo de una singular y persistente virulencia, desbaratando todas las ideas recibidas sobre previsión y cálculo en la vida social, política y económica (Braudel, 1984, vol. III: 59). La crisis, sin embargo, es un mecanismo regular del sistema, al que hay que despojar de sus connotaciones depresivas, una vez admitido que su escenario es el sistema mundial en su conjunto. En toda crisis, pues, determinadas áreas y determinados grupos particulares mejoran su posición en la División Internacional del Trabajo, del mismo modo que los auges no benefician por igual a todo el mundo. El occidentalocentrismo, sin embargo, identifica las crisis con periodos en los que las rentas de las «burguesías asalariadas» del centro sufren recortes significativos.

Las mutaciones económico-sociales durante la crisis pueden entenderse muy bien desde esta perspectiva. Por una parte, el desempleo disciplina las demandas del trabajo organizado en los países centrales, e invierte las relaciones de poder entre capital y trabajo en favor del primer polo. El mantenimiento de un desempleo elevado no es, además, una consecuencia del funcionamiento de impersonales e inexorables leyes económicas, o de la adaptación a nuevas e inevitables condiciones productivas. Es, simplemente, el corolario obligado de políticas explícitas que han primado determinados modelos de innovación tecnológica y determinadas formas de inserción de esos modelos, que han facilitado la movilidad del capital y la reducción de los costes salariales -a través de la desindustrialización selectiva, de las nuevas formas de organización industrial, de la terciarización, etc.-, y que han fomentado el fortalecimiento de las rentas del capital frente a las del trabajo, y de la economía nominal frente a la productiva. Un cuadro de deflación constante, de mejoras contínuas en la productividad, y de insuficiente crecimiento de la demanda real, no contribuye a generar oportunidades para la creación de empleo suficiente.

La crisis, pues, y su gestión ortodoxa, sólo es inexorable desde el punto de vista de los intereses que protege y amplía, para los que, efec- 
tivamente, las inercias keynesianas y las redistribuciones estatales resultan profundamente contraproducentes (Torres López, 1995). La investigación abstracta sobre las causas de los fenómenos económicos no debería eludir, sin embargo, preguntas más sencillas, cuya claridad no pocas veces contribuye a enturbiar: ¿quién decide, y para quién? (Chomsky, 1993: 20). Sólo sobre este interrogante es posible construir una teoría coherente de la crisis y de sus consecuencias.

Desde esta óptica, los procesos de informalización pueden comprenderse como un instrumento de gobierno de la crisis, que desata consecuencias imprevistas y, a medio plazo, tal vez efectos indeseados desde el punto de vista de los arquitectos de las políticas vigentes en las últimas décadas. Al proletarizar parcialmente nuevos contingentes de mano de obra en los países periféricos y semiperiféricos se ceba la bomba de futuros conflictos, ya que la mercantilización progresiva y la destrucción de los nichos de autosubsistencia incrementa la dependencia de las rentas salariales para la supervivencia de los grupos domésticos. La ampliación de la mercantilización constituye la más profunda oportunidad de politización, como han escrito Balibar y Wallerstein (1991: 177). En los países centrales, por otra parte, la vía regia para quebrar los marcos institucionalizados del mercado de trabajo y la capacidad contractual del trabajo organizado consistió en la apertura de los mercados de trabajo a las categorías sociales implícitamente excluidas en el periodo fordiano -mujeres, jóvenes, inmigrantes-, aunque frecuentemente en condiciones de precariedad y/o informalidad, y en la antagonización competitiva de la fuerza de trabajo sobre el fondo de un desempleo rampante. La combinación de los procesos de informalización y de una intensificada «polarización fragmentada» (Mingione, 1993: 536) del mercado de trabajo modificó drásticamente la estructura social, y la percepción que los distintos grupos tienen de su acción y de sus intereses (Castells y Portes, 1989). La apertura de los mercados de trabajo consagró una realidad laboral en la que los individuos no sólo son exhortados a no mantener vínculos de grupo, sino a defender intereses divergentes, cuando no mutuamente excluyentes (Bilbao, 1993; Gorz, 1995).

Como señalaron, en efecto, Castells y Portes, la informalidad se apoyó, de entrada, en la colusión coyuntural entre los grupos anteriormente excluidos del mercado de trabajo regular, deseosos por distintos motivos de participar en una actividad laboral cuya rarificación incrementa subjetivamente su prestigio, y los productores, ávidos de eludir las regulaciones estatales y rebajar el coste de la mano de obra (Castells y Portes, 1989). La segmentación permite disponer la antagonización de unos grupos frente a otros, conforme a la geometría variable de pasiones cambiantes e intereses inmóviles. Dichas prácticas no son, por otra parte, nuevas, como ilustra el mercado de trabajo 
desregulado del siglo XIX. Tampoco son necesariamente duraderamente exitosas. La absorción paulatina de la fuerza de trabajo femenina «inactiva» (sic) permite replantear la función del trabajo doméstico y la persistencia del sexismo, no como un beneficio (incidental e históricamente cambiante) para los «hombres», sino como un requisito (estructural) para rebajar el coste de la mano de obra. La adscripción de la minorías étnicas a los trabajos más duros y peor pagados, indeseados por los nacionales, amenaza tendencialmente con la recomposición de las «dos naciones» en el seno mismo de las grandes ciudades de los países centrales, en cuyos guetos se hacinan un número creciente de personas -iqueríamos mano de obra y vinieron personas!- sin derechos económicos, sociales, políticos o culturales.

De momento, la «informalidad» ha funcionado como una especie de «costura», que muestra y, al mismo tiempo, contiene los efectos más dramáticos de la crisis social y del empleo (Pérez Díaz, 1996: 149158). La desagregación del trabajo, a la que los procesos de informalización han contribuido decisivamente, ha permitido además cortocircuitar la relación entre la proletarización de hecho y la experiencia de la misma, al disponer multitud de mediaciones entre los empleados y los empleadores últimos -en las subcontrataciones en cascada, en el trabajo a domicilio sostenido, en último término, por una invisible «tela de araña financiera»-. La constante recreación de un terciario descualificado y el mantenimiento de actividades tradicionales, organizadas sobre una base recíproca, provee las bases para la subsistencia de multitud de muy pequeñas empresas poco capitalizadas, auténticos nichos protectores frente al desempleo, resistentes pese a la merma de los beneficios. Las adelgazadas capas de trabajadores estables, multicualificados y polivalentes, son inducidas a velar por sus privilegios, en detrimento de las solidaridades grupales o de clase (Gorz, 1992).

El porvenir de estas tendencias contradictorias, que afectan a la continuidad del sistema tal como lo conocemos, es incierto. Si la esperanza de integración y participación paulatina de más y más grupos en los beneficios del sistema se desvanece, los mecanismos institucionales que aseguraron su estabilidad -el nacionalismo económico, el desarrollismo, el Welfare, la democracia, la meritocracia- también entran en crisis. Si la promesa de mejora gradual se desacredita, entonces el apaciguamiento tampoco es posible. Se quebraría, así, la fe en la ideología hegemónica del liberalismo, incapaz de reconocer mayores derechos políticos y mayor redistribución económica sin que el sistema mismo se vea amenazado (Wallerstein 1993). Sólo el futuro, por otra parte, que se construye con nuestras decisiones, despejará las incógnitas sobre la posibilidad de un nuevo Pacto Social y la efectividad del universalismo, o de alternativas que, en principio, se me antojan poco atractivas y un tanto deprimentes. 


\section{BIBLIOGRAFÍA}

ARRIGHI, G.: Una crisis de hegemonía, en VV. AA.. Dinámica de la crisis global. Siglo XXI. México,1983. «Costumbre e innovación: ondas largas y estadios de desarrollo capitalista». Zona Abierta. Siglo XXI. Madrid, $1987,43 / 44$.

BAGNASCO, A. (comp.): L' altra metà della economía. Ligouri. Nápoles, 1986. La costruzione sociale del mercato. Il Mulino. Bolonia, 1988.

BALIBAR, E. Y WALLERSTEIN, I.: Raza, nación, clase. IEPALA. Madrid, 1991.

BILBAO, A.: Obreros y ciudadanos. La desestructuración de la clase obrera. Trotta. Madrid, 1993.

BOYER, R.: La teoría de la regulación: un análisis crítico. Alfons el Magnánim. Valencia, 1992.

BRAUDEL, F.: Civilización material, economia y capitalismo, siglosXV-XVIII (3 vols.). Alianza. Madrid,1984. La dinámica del capitalismo. Alianza. Madrid, 1985.

BUSTELO, P.: Economía política de los nuevos países industriales asiáticos. Siglo XXI. Madrid, 1990.

CAPECCHI, V.: Economía informal y desarrollo de especialización flexible, en SANCHIS, E. Y MIÑANA, J. (eds.): La otra economía, trabajo negro y sector informal. Alfons el Magnánim. Valencia, 1988.

CAPECCHI, V. Y PESCE, A., "Si la diversidad es un valor», Debats, IVEI, Valencia, 1985, 10.

CAPIELLO, M.A.: «Propuesta de bibliografía razonada sobre la economía sumergida en la industria (Italia, 1970-1982)». REIS. Madrid, 1987, 38.

CASTELLS, M. y PORTES, A.: World underneath: the origins, dynamics, and effects of the informal economy, en PORTES, A., CASTELLES, M. Y BENTON, L.: The informal economy. Studies in advanced and less developed countries. The John Hopkins University Press. Baltimore y London, 1989.

CELADA, F.; LÓPEZ GROH, F. y PARRA, T.: Efectos espaciales de los procesos de reorganización del sistema productivo en Madrid. Consejería de Ordenación del Territorio. Madrid, 1985.

CHAMOUX, M.N.: «Sociétés avec et sans concept de travail». Sociologie du Travail. Paris, 1994, Hs XXXVI.

CHOMSKY, N.: Año 501, la conquista continúa. Ed. Libertarias. Madrid, 1993.

DE SOTO, H.: El otro sendero. La revolución informal. Oveja Negra. Bogotá, 1987.

ESTEVAN, A. (comp.): F.M.I., Banco Mundial y GATT. Cincuenta años bastan. Talasa. Madrid,1995.

FREY, L.: Lavoro a domicilio e decentramento dell' attività produttiva nei settori tessile e dell' abigliamento. Franco Angeli. Milano, 1975. 
FREYSSENET, M.: «Los enigmas del trabajo: nuevas pistas para su conceptualización». Economía y Sociología del Trabajo. Ministerio de Trabajo y Seguridad Social. Madrid, 1994, 23-24.

GALLINO,L.: «Ripensare l' economía». Inchiesta, 1983,59-60.

GAROFOLI, G.: Decentramento produttivo, mercato de lavoro e localizzacione industriale, en VV.AA.: Ristrutturacione industriale e territorio. Il Mulino. Bolonia, 1978.

GERMANI, G.: El concepto de marginalidad. Nueva Visión. Buenos Aires, 1980.

GERSHUNY, J.I. y PAHL, R.E.: "Inglaterra en el decenio de las tres economías». Alfoz. Madrid, 1983, 35.

GIDDENS, A.: Más allá de la izquierda y la derecha. El futuro de las políticas radicales. Cátedra. Madrid, 1996.

GORZ, A.: «La declinante relevancia del trabajo y el auge de los valores posteconómicos». El Socialismo del Futuro. Madrid, 1992, 6. "Salir de la sociedad salarial». Debats. Valencia, 1994, 50. Metamorfosis del trabajo. Sistema. Madrid, 1995.

HART, L.: «Informal income opportunities and urban employment in Ghana». Journal of Modern African Studies. 1973, 11.

HOBSBAWM, E.: Historia del siglo XX, 1914-1991. Crítica. Barcelona,1995.

LATOUCHE, S.: El planeta de los náufragos. Ensayo sobre el posdesarrollo. Acento. Madrid, 1993.

MARTÍNEZ VEIGA, U.: El otro desempleo. La economía sumergida. Cuadernos de Antropología, Anthropos. Barcelona, 1989.

MINGIONE, E.: Las sociedades fragmentadas. Ministerio de Trabajo y Seguridad Social. Madrid, 1993.

NUN, J.; MARTIN, J.C. y MURMIS, M.: «La marginalidad en América Latina». ILPES- DESAL. Santiago de Chile, 1967, 2.

OFFE, C.: «¿Pleno empleo?». Debats. Valencia, 1994, 50.

PAHL, R.E.: «De l'economía informal a formes de treball: models $i$ tendències». Papers. Barcelona, 1990, 34. Divisiones del trabajo. Ministerio de Trabajo y Seguridad Social. Madrid, 1991.

PÉREZ DÍAZ, V.: España puesta a prueba 1976-1996. Alianza. Madrid,1996.

POLANYI, K.: La gran transformación. La Piqueta. Madrid, 1989.

PORTES, A.; CASTELLES, M. y BENTON, L.: The informal economy: studies in advanced and less developed countries. The John Hopkins University Press. Baltimore y London, 1989.

PORTES, A. y SCHAUFFLER, R.: The informal economy in Latin America: definition, measurement and policies, en SCHOEPFLE, G. K. Y PÉREZ LÓPEZ, J.: Work without protections. Bureau of International Labor., U.S.Department of Labor, Washington D.C., 1993.

SABEL, Ch.: Trabajo y política. La división del trabajo en la industria. Ministerio de Trabajo y Seguridad Social. Madrid, 1985. 
SACHS, I.: «La crisi, il progreso tecnico e l'economia somersa». Inchiesta, 1983, 59-60.

SANCHIS, E.: El trabajo a domicilio en el País Valenciano. Instituto de la Mujer. Madrid, 1984.

SANCHIS, E. y MIÑANA, J.: La otra economía. Trabajo negro y sector informal. Alfons el Magnànim. Valencia, 1988.

TORRES LÓPEZ, J.: Desigualdad y crisis económica. El reparto de la tarta. Sistema. Madrid, 1995.

TORTOSA, J.M.: «La economía sumergida en la provincia de Alicante: el juego de las máscaras». REIS. Madrid, 1988, 41.

WALLERSTEIN, I.: La crisis como transición, en VVAA: Dinámica de la crisis global. Siglo XXI. Madrid, 1983. «Las ondas largas como proceso capitalista». Zona Abierta. Madrid, 1985, 34-35. El capitalismo histórico. Siglo XXI. Madrid, 1988. Análisis de los sistemas mundiales, en GIDDENS, A. y TURNER, J.: La teoría social hoy. Alianza. Madrid, 1990. El descrédito del liberalismo, en VVAA: El orden mundial tras la Guerra del Golfo. Juan Gil-Albert. Alicante, 1993.

YBARRA, J.A.: Diez años de economía oculta en España, en SANCHÍS, E. y MIÑANA, J.: La otra economía. Alfons el Magnànim. Valencia, 1988. "La racionalidad económica de la industria descentralizada». Sociología del Trabajo. Madrid, Extra 1991. 